\title{
Assessment of pest insects of Capsicum annuum L.1753 (Solanaceae) in a cultivation cycle in Yaoundé
}

\author{
Champlain DJIETO-LORDON ${ }^{1}$, Cyril Roméo HEUMOU ${ }^{1,2 *}$, Pierre Stephan ELONO \\ AZANG $^{4}$, Chantal Désirée ALENE ${ }^{1}$, Alain carmel NGUENG ${ }^{1}$ and Pierre NGASSAM ${ }^{3}$ \\ ${ }^{1}$ University of Yaoundé I, Faculty of Science, Department of Animal Biology and Physiology, \\ Laboratory of Zoology, PO BOX.812 Yaoundé, Cameroon. \\ ${ }^{2}$ University of Bamenda. Higher Teaching Training College, Department of Biology, \\ PO BOX 39 Bamenda, Cameroon. \\ ${ }^{3}$ University of Yaoundé I, Faculty of Science, Department of Animal Biology and Physiology, \\ Laboratory of Parasitology, PO BOX.812 Yaoundé, Cameroon. \\ ${ }^{4}$ University of Yaoundé I, Higher Teaching Training College, Department of Biology, \\ Laboratory of Zoology, PO BOX 47 Yaoundé, Cameroon. \\ *Corresponding author; E-mail: hcyrilromeo@yahoo.fr $\quad$ Tel. (+237) 77286181
}

\begin{abstract}
Pepper, Capsicum annuum is appreciated in tropical regions for its taste and its ability to increase the appetite level of food. This study aimed at investigating pest insects' diversity of pepper right from pricking out to harvest. It also examined how aphids and whiteflies populations vary in the plant's life cycle and specific fruit pests' effects on the yield. During five months, individual plant organs were examined weekly. Insects encountered were captured, counted and identified. Immature stages were bred for identification purposes. Regular sampling allowed us to identify 28 species from 7 orders. During the pre-flowering phase, 5 orders were obtained: Hemiptera, Hymenoptera, Coleoptera, Lepidoptera and Orthoptera. The same orders were found at Flowering-fruiting phase, with appearance of one new order, the Thysanoptera. At this stage, exponential growth of Hemiptera and Hymenoptera was also observed. During maturation, Diptera and Lepidoptera were the most abundant pests. Ceratitis capitata and Cryptophlebia leucotreta were responsible for yield losses (20.46\%). Aphids and whiteflies affected plant's fitness, either directly through sap sucking or indirectly through viral transmissions. Ants'transport, disseminate and protect Hemipterans. Since plants phenology influences pest diversity, it should be taken into account in the efforts of developing IPM strategies.
\end{abstract}

(c) 2014 International Formulae Group. All rights reserved.

Keywords: Spice, phenology, yield, IPM.

\section{INTRODUCTION}

Pepper is a largely widespread spice. Annual world production of pepper in the year 2004 was evaluated to 23 million tons from a total of 1.54 million ha (Sunitha, 2007). China is the world's major producer of Capsicum with an area of 0.61 million ha and a production of 120 million tons (Sunitha, 2007). On the one hand, the hot pepper variety which is considered as a traditional spice is cultivated near the dwellings, and is sold in all the markets in tropical Africa. On the other 
hand, the sweet pepper variety is an exotic vegetable which was recently introduced into the area (Grubben and Denton, 2004). In Cameroon, exact statistics of pepper production are not available, but it is really recognised that the market price of this spice is constant on the rise. This growth is attributed to the high demand from the Cameroon urban areas. In Yaoundé and other towns of Cameroon, hot and sweet peppers (Capsicum annuum) appear among the most current spice species. They are consumed in various culinary preparations: fresh, dried or used for salads, in association with other vegetables. As a consequence of extreme increase in local consumption of pepper, farmers are increasing their pepper growing areas. However, this tasty spice is being attacked by many pest insects which reduce their fitness and production. Quite a few reports and Masters Dissertations have been conducted to identify the insect pests of Capsicum annuum in Cameroon (DjietoLordon and Aléné, 2002; Elono Azang, 2007). Therefore, to provide new information to these data bases that can improve Integrated Pest Management strategies (IPM), we carried out a survey on pepper pests in southern Cameroon. Thus, the objectives in the present study were: to identify the insect diversity associated with the plant phenology of different pepper cultivars; to examine how the abundance of Aphid and whitefly populations vary in the life cycle of the plants; and to evaluate the effect of specific fruit pests on the yield.

\section{MATERIALS AND METHODS Study site}

The study was carried out in an urban zone of Yaoundé, a town situated in the forest area of the South-Cameroonian plate, located between longitudes $3^{\circ} 27^{\prime} / 4^{\circ} 10^{\prime} \mathrm{N}$ and the latitudes $11^{\circ} 32^{\prime} / 11^{\circ} 49^{\prime} \mathrm{E}$ (Letouzey, 1968). In 2007, the town received $2143.8 \mathrm{~mm}$ of rain and an annual average temperature of $24.59{ }^{\circ} \mathrm{C}$. The temperatures are almost constant and the monthly averages oscillate between 23.5 and $25.8{ }^{\circ} \mathrm{C}$. The data was recorded during the rainy and the dry seasons between October 2007 and February 2008.

\section{Experimental design}

A surface of $300 \mathrm{~m}^{2}$ was cultivated. A total of fifteen (15) ridges made each cycle of cultivation following local techniques of cultivation. Each ridge measured $8 \mathrm{~m}$ long and $1 \mathrm{~m}$ wide. The varieties locally cultivated are red, yellow and sweet peppers. Five (5) ridges were used to plant each pepper variety. Poultry manure was used to improve soil fertility. On each ridge, 12 seedlings were planted on two lines and spacing of $0,7 \mathrm{~m}$ between the plants of the same line and $0,6 \mathrm{~m}$ between the plants of two different lines. A total of 60 seedlings of each solanaceous species were planted, and all were systematically sampled.

\section{Data collection}

Based on visual observations, each plant organ (leaves, flowers, fruits) was individually examined twice a day, and once per week, that is, in the morning and in the afternoon. Insects encountered were captured and counted. Immature stages of Lepidoptera and Diptera were brought up to imaginal moult for identification purposes. The sampling period was divided into three phenological stages: pre-flowering, floweringfruiting and maturation. The total number of insects captured in one phase was summed up as absolute abundance of the pest. In order to study the dynamics of Aphids and whitefly populations, all the specimens found in leaves and flowers were counted weekly during the evolution of each plant variety. The mean numbers of insects counted per infested leaves were used to set out a curve of their population evolution. To evaluate the effect of specific fruit pests on the yield, we used the ratio of the numbers of fruits of each plant cultivar having undergone attacks by the total numbers of fruits harvested. The identification was done with the Key of Delvare and Aberlinc (1989), Betbeder and Matibet (1989), and Etienne et al. (1992).

\section{Statistical analysis}

The data was continuous and temporally independent. We used the Fisher test of ANOVA to appreciate the variation of 
attack rates during the different harvests. This was done in version 12.4 of SPSS software.

\section{RESULTS}

\section{Arthropod fauna}

Diversity of insects associated with the plant phenology of different pepper cultivars consists of seven orders. These orders are made up of Hymenoptera, Hemiptera, Coleoptera, Diptera, Lepidoptera, Orthoptera and Thysanoptera (Figure 1).

In the pre-flowering phase, 10 species from 9 families and 5 orders were identified. The relative abundance of insect pests obtained during this first phase of plant's life cycles showed that hot red pepper, hot yellow pepper and sweet pepper were dominated by the orders of Hemiptera (524-3445 individuals) and Hymenoptera (107- 492 specimen caught) Table 1.The first group, the order of Hemiptera are sap-sucker insects which derive their food at the level of the leaves and young stems of the plants. Species like Bemisia tabaci and Macrosiphum euphorbiae (Thomas) cause direct damage by reducing the quantity of circulating sap, rolling up and shrivelled plants. They also cause indirect damages on the young plants by infecting them with viruses that are responsible for the Solanacea curling and yellow coloration tasks on the leaves. The second group of pests (Hymenoptera) is also abundant, but its damaging action on the plants is indirect; Pheidole megacephala is the only species of ants present on the field during the study period. These ants transport the Hemiptera (Bemisia tabaci and Macrosiphum euphorbiae) and deposit them on the young buds of the plants, thus contributing to the dissemination and the protection of these aphids in the farm. Orthopteran, Thysanopteran and Coleopteran populations were not significant (Table 1).

At the flowering phase, 7 species from 7 families and 5 orders were identified. All like previous phase, the orders of Hemiptera (2024-74465 individuals) and Hymenoptera (2648- 10592 specimen caught) were dominant. But the difference was based on individual abundance of each group obtained during the pre-flowering phase. The abundance of Hemipterans and Hymenoptera populations increase exponentially and multiplied for more than ten times compared to the one of the pre-flowering stage (Table 2). The damage they cause was the same with the previous stage in addition to the fact that many flowers were destroyed by sucking at the base of the flower.

In the third phase of the plant's life cycle considered as the maturation phase, the abundance of Hemiptera (218-399 specimens) and Hymenoptera (102-192 specimens) decreases drastically until it reaches the level of the population obtained of the preflowering phase. However, two new groups of insects which attack only the fruits can be found here: the Lepidoptera (Crytophlebia leucotreta, Leucinodes orbonalis) and Diptera (Ceratitis capitata). Although the Lepidopteran and the Dipteran populations were smaller in number as compared to the two previous orders that are Hemiptera and Hymenoptera, their larvae caused heavy damages on pepper fruits at the fructification period. Actually, the larvae of these insects feed on fruits' pupa and the destruction of these fruits' tissues precipitates them on the ground before maturation, thus causing a decrease in yield (Table 3).

\section{Population fluctuations of aphids and whiteflies}

The population size of aphids and whiteflies on hot red pepper was evaluated from October 2007 to February 2008, corresponding to 22 weeks of observation (Figure 2). The average abundance of aphids' population show four evolutionary phases depending on the life cycle of the plant:

(i) Phase 1 (week 1 to 3 ), during which the average number of aphids were low (around $3 \pm 1.13$ aphids/plant, Min=0, $\operatorname{Max}=12, \mathrm{~N}=40)$;

(ii)Phase 2 (week 3 to 9): during this phase the average number of aphids increased exponentially, until a maximum of abundance around week 9 (56. 34+5. 69 aphids/plant, $M i n=20, \operatorname{Max}=120, \mathrm{~N}=40$ );

(iii) Phase 3 (week 9 to 14) here, the aphids population was maintained high $(26 \pm 2$. 83 aphid/plant, Min=18, $\operatorname{Max}=35, \mathrm{~N}=40$ ); 
(iv) Phase 4: during phase 4, the aphids population decreases gradually until it becomes null at the end of the plant's life cycle $(8 \pm 0.83$ aphid/plant, Min=2, $\operatorname{Max}=18, \mathrm{~N}=40$ ).

The population of whiteflies can be summarized into two principal phases:

(i) The population was not important during the first cycle of the plant at the preflowering period. It was lower than 10 individuals $\quad(0 . \quad 5 \pm 0.49 \quad$ mean whitefly/plant, $\mathrm{Min}=0$, $\mathrm{Max}=8, \mathrm{~N}=40$ );

(ii) From week 13 to 22 , the specimens increased gradually until a maximum at the end of the plant's life cycle $(16.5 \pm 3.6$ whitefly/plant, Min=12, $\operatorname{Max}=22, \mathrm{~N}=40)$; (Figure 2).

\section{Population fluctuation of aphids and whiteflies on sweet pepper \\ The population size of aphids ( $A$.} gossypii) and whitefly (B. tabaci) was evaluated during the same period of study (Figure 3), this was extending to 16 weeks of observation. During this period, the average number of aphids showed three principal phases:

(i) During the first phase between week 1 and week 3 , the aphids population was little $(10 \pm 1.69$ whitefly/plant, $\operatorname{Min}=9, \operatorname{Max}=12$, $\mathrm{N}=40$ );

(ii) During the second phase between week 3 and 5 , the population grew rapidly until it reached the maximum at week 5 , the average number of individuals was 39 . $5 \pm 3.13 \mathrm{aphid} /$ plant, $\operatorname{Min}=10, \operatorname{Max}=50$, $\mathrm{N}=40$;

(iii) The third phase between week 5 and week 12 during which the population was maintained $(28 \pm 2.69$ whitefly/plant, $\operatorname{Min}=15, \operatorname{Max}=42, \mathrm{~N}=40$ );

(iv)The last phase corresponds to a reduction in aphids until the end of the sampling at the sixteenth week $(9.5 \pm 2.73$ aphid/plant, Min=2, Max=20, N=40).

The whitefly population on sweet pepper like the hot pepper was low during the first phase of plants life cycle, i.e at the preflowering and the middle of fructification phases $(4.83 \pm 0.77$ whitefly/plant, $\mathrm{Min}=0$, $\operatorname{Max}=10, \mathrm{~N}=40$ ). This population started growing at the end of the maturation phase of the plant between the third and last weeks of observation. Mean aphids per plant was

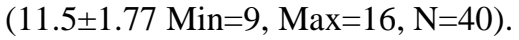

Fluctuation of aphid and whitefly populations on yellow pepper

The study of population fluctuation of Aphids on yellow pepper shows the same for hot red pepper, with three principal phases (Figure 4):

(i) The phase between week 1 and 3 during which the population of Aphids increased in size until reaching a peak at the first week of sampling $(8 \pm 1.79$ aphid/pant, Min=2, $\operatorname{Max}=20, N=40$ );

(ii) The second phase (week 4 to 9) of exponential increase in population during which the peak of insect pullulating was obtained around week $9 \quad(30 \pm 5.73$ aphids/plant, $\operatorname{Min}=4, \operatorname{Max}=58, \mathrm{~N}=40$ );

(iii) The phase of week 9 to 15 during which the insect pullulating was highly maintained $\quad(48 \pm 6.34 \quad$ aphids/plant, $\mathrm{Min}=40, \operatorname{Max}=60, \mathrm{~N}=40)$;

(iv) The phase of week 16 to 22 where we noted a brutal fall of Aphids population until a minimum at week $22(9 \pm 2.61$ aphids/plant, $\operatorname{Min}=4, \operatorname{Max}=20$ ).

Concerning whiteflies, their population was divided into three principal phases:

(i) The population was low from week 1 to week 8 ; they were $\leq$ to 10 individuals per plant;

(ii) The second phase was characterised by a small growth of whitefly population. This increase appears at the beginning of the flowering phase. The number of individuals were greater than 10/plant until a maximum was attained at the end of the plant's cycle at week 22. (Figure 4).

\section{Impact of fruit pests on the yield Impact on sweet pepper}

The damage caused on the sweet pepper fruits was due to $C$. leucotrecta (Figure 5). Thus, 9 fruits only were attacked by this Lepidoptera, the loss of production was evaluated to $12.85 \%$. During this farming period, the damage caused by $C$. leucotreta 
did not have a significant variation between the harvests $(\mathrm{F}=0.11$; ddl $=3 ; \mathrm{P}=0.951)$.(Figure 5).

\section{Impact on hot red pepper}

During the study period, 7 harvests were done. This enabled us to collect 1278 fruits on hot red pepper among which 281 presented being attacked by carpophages. This represents a damage of production of about $21.98 \%$. The most significant fruit loss was due to C. leucoterta which affected 190 fruits, which is $14.86 \%$ of the production (Figure 6). The Dipterans and the other bio attackers (Birds and molluscs) were respectively in charge of $2.42 \%$ (31 attacked fruits) and $3.91 \%$ (50 attacked fruits) of the losses. The losses of production due to various pests; both the fruit-eaten insects and the bio attackers statistically varies from one harvest to another in the same culture cycle $(\mathrm{F}=3.082 ; \mathrm{ddl}=6$; $\mathrm{P}=0.006$ for C. capitata; $\mathrm{F}=12.997$; ddl=6; $\mathrm{P}=0.001$ for $C$. leucotreta; and $\mathrm{F}=4.353$; $\mathrm{ddl}=6 ; \mathrm{P}=0.001$ for the other bio attackers) (Figure 6)

\section{Impact on yellow pepper}

On yellow pepper, we collected, during the same period of study as that on hot red pepper in 7 harvests, a total of 1325 fruits, among which 352 were attacked by carpophages (either $26.56 \%$ of the production). The ascribable attacks in Lepidoptera were about $15.09 \%$ (200 attacked fruits) against $6.71 \%$ (89 attacked fruits) by the Diptera ones and $4.75 \%$ (63 attacked fruits) by the other bio attackers (birds, molluscs and burns). Contrary to the hot red pepper (Figure 6), the rate of the ascribable damage by $C$. capitata did not vary significantly according to the harvests $(\mathrm{F}=$ 1.75; $\mathrm{ddl}=6 ; \mathrm{P}=0.109$ ). On the other hand, those ascribable by $C$. leucotreta and other bio-attackers showed a remarkable and statistically significant difference between the harvests $(\mathrm{F}=4.29 ; \mathrm{P}=0,001$ and $\mathrm{F}=3.73 ; \mathrm{P}$ $=0.001$ respectively) (Figure 7).

The results of our study show that the three varieties of pepper show the same variable degrees of the carpophages infestation apart from $C$. capitata which was absent on the sweet pepper. However, the species $C$. leucotreta was responsible for the most serious damage inflicted to $C$. annuиm with $43.80 \%$ (399 attacked fruits) of the losses against $9.13 \%$ (120 attacked fruits) for $C$. capitata (on yellow and red peppers exclusively).

Table 1: Absolute abundance of pest insects species on Capsicum annuum cultivars in the preflowering phase in Yaoundé, Cameroon, 2007.

\begin{tabular}{lcccc}
\hline Orders & Species & Red pepper & Sweet pepper & Yello wpepper \\
\hline Hemiptera & Bemisia tabaci & 1123 & 524 & 3231 \\
Hemiptera & Macrosiphum euphorbiae & 453 & 0 & 214 \\
Hemiptera & Jacobiasca sp. & 0 & 0 & 3 \\
Hemiptera & Epitrix sp. & 0 & 0 & 4 \\
Hemiptera & Lema sp. & 0 & 0 & 1 \\
Coleoptera & Cheilomenes lunata & 0 & 0 & 3 \\
Coleoptera & Gn.l lsp.1 & 0 & 0 & 1 \\
Orthoptera & Delphacoïdes campestris & 5 & 3 & 2 \\
Hymenoptera & Pheidole megacephala & 492 & 474 & 107 \\
Lepidoptera & Spodoptera littoralis & 1 & 0 & 2 \\
\hline
\end{tabular}


Table 2: Absolute abundance of pest insects' species on Capsicum annuum cultivars in the flowering-fructification phases in Yaoundé, Cameroon, 2007.

\begin{tabular}{lcccc}
\hline Orders & Species & Red pepper & Sweet pepper & Yellow pepper \\
\hline Hemiptera & Bemisia tabaci & 74066 & 1851 & 73782 \\
Hemiptera & Macrosiphum euphorbiae & 403 & 173 & 215 \\
Coleoptera & Gnlsp.1 & 10 & 3 & 16 \\
Thysanoptera & Frankliniella occidentalis & 25 & 19 & 21 \\
Hymenoptera & Pheidole megacephala & 10592 & 2648 & 9425 \\
Orthoptera & Zonocerus variegatus & 1 & 1 & 2 \\
Orthoptera & Gnl sp.1 & 1 & 0 & 3 \\
\hline
\end{tabular}

Table 3: Absolute abundance of pest insects' species on three Capsicum annuum varieties in the Maturation phase in Yaoundé, Cameroon, 2007.

\begin{tabular}{lcccc}
\hline Orders & Species & Red pepper & Sweet pepper & Yellow pepper \\
\hline Hemiptera & Macrosiphum euphorbiae & 230 & 176 & 210 \\
Hemiptera & Bemisia tabaci & 116 & 42 & 189 \\
Hemiptera & Delphacoïdes campestris & 6 & 6 & 4 \\
Hemiptera & Jacobiasca sp. & 0 & 0 & 3 \\
Hemiptera & Cochenille & 1 & 1 & 47 \\
Thysanoptera & Frankliniella occidentalis & 10 & 12 & 9 \\
Hymenoptera & Pheidole megacephala Fabricius & 120 & 192 & 102 \\
Coleoptera & Gn.2sp.1 & 387 & 387 & 417 \\
Coleoptera & Scymnus sp. & 0 & 0 & 17 \\
Coleoptera & Lagria vilosa & 1 & 1 & 1 \\
Orthoptera & Zonocerus variegatus & 0 & 0 & 1 \\
Orthoptera & Epitrix sp. & 0 & 0 & 2 \\
Orthoptera & Paratetrix sp. & 2 & 2 & 2 \\
Lepidoptera & Cryptophlebia leucotreta & 1452 & 348 & 1536 \\
Lepidoptera & Spodoptera littoralis & 3 & 0 & 2 \\
Lepidoptera & Chrysodeixis calcitesEsper & 2 & 0 & 0 \\
Diptera & Paragus borbonicus & 110 & 61 & 140 \\
Diptera & Ceratitis capitata & 2472 & 0 & 2640 \\
\hline
\end{tabular}




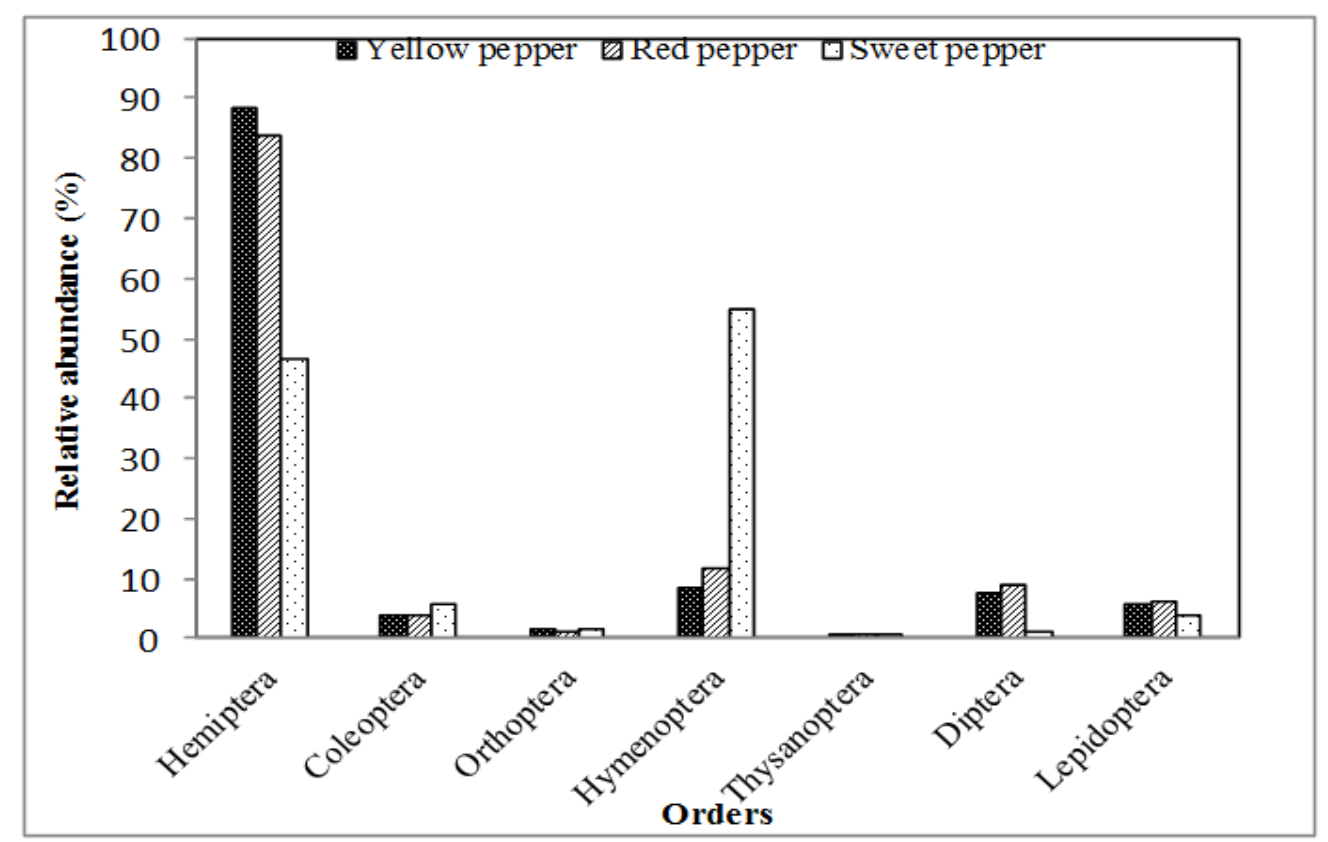

Figure 1: Relatives abundances of the various orders of pest insects associated with Capsicum annuиm (hot red, yellow and sweet pepper) in the experimental plot within the campus of the University of Yaoundé I between October 2007 and February 2008.

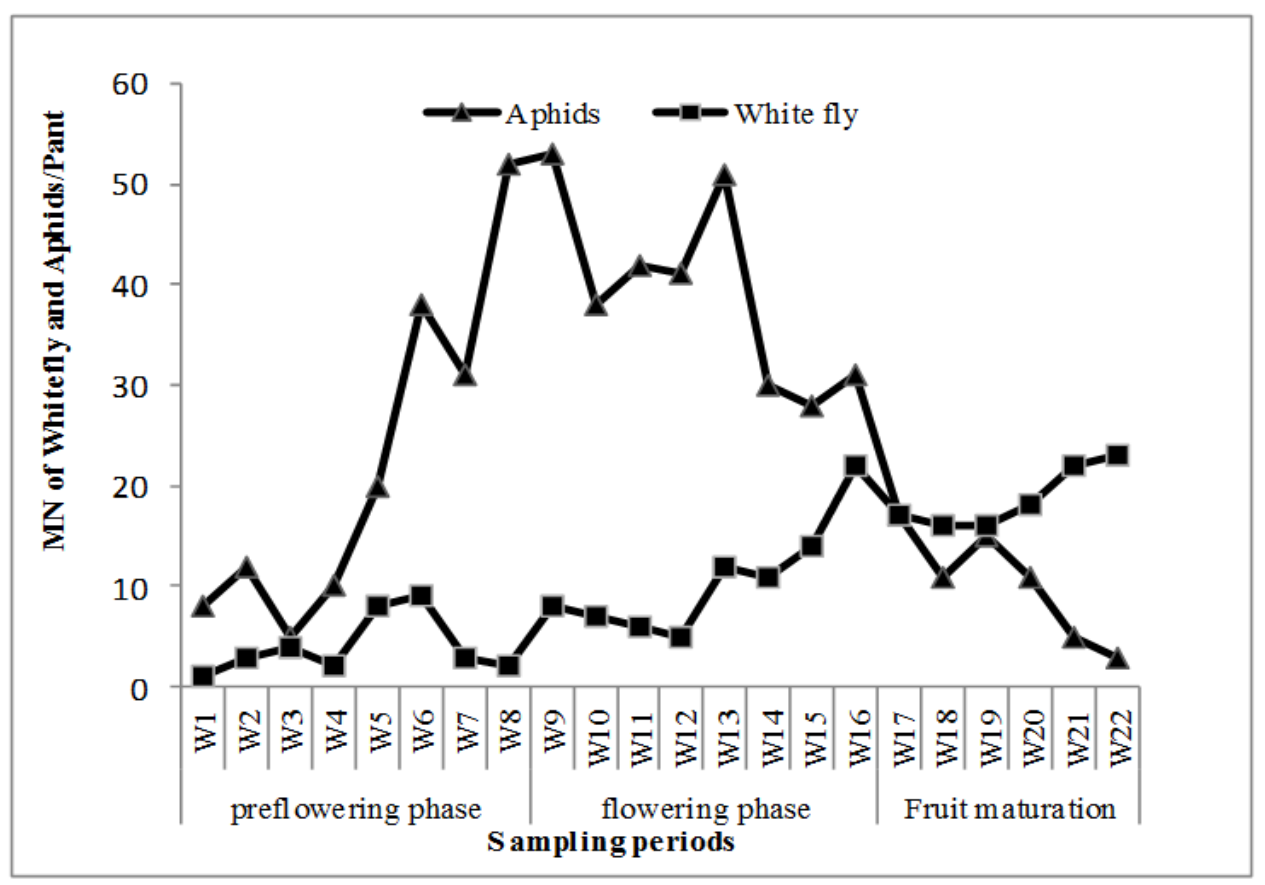

Figure 2: Temporal variations of aphid and whitefly populations associated with hot red pepper in the experimental plot within the campus of the University of Yaoundé I between October 2007 and February 2008. MN = Mean Number. 


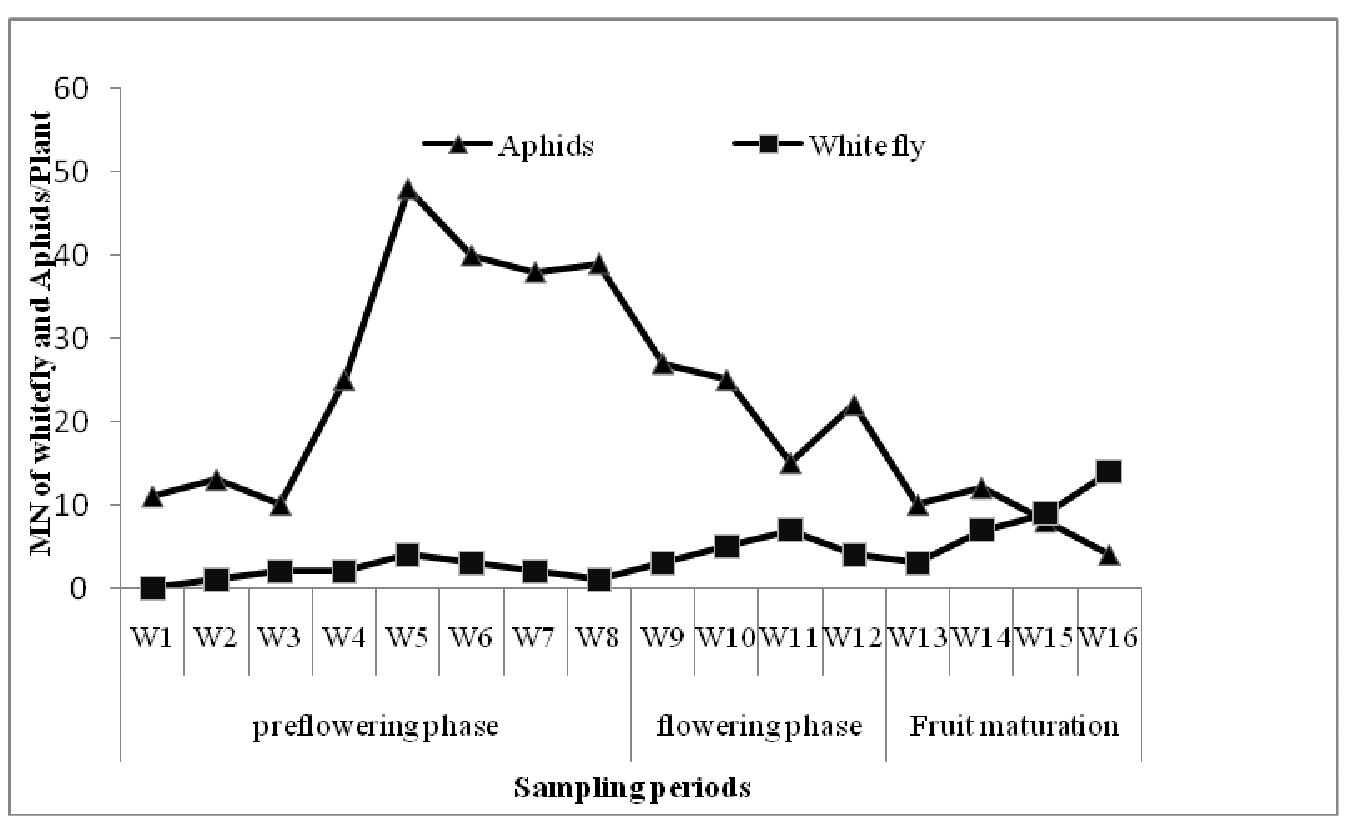

Figure 3: Temporal variation of aphid and whitefly populations associated with sweet pepper in the experimental plot within the campus of the University of Yaoundé I between August 2007 and January 2008. MN: Mean Number.

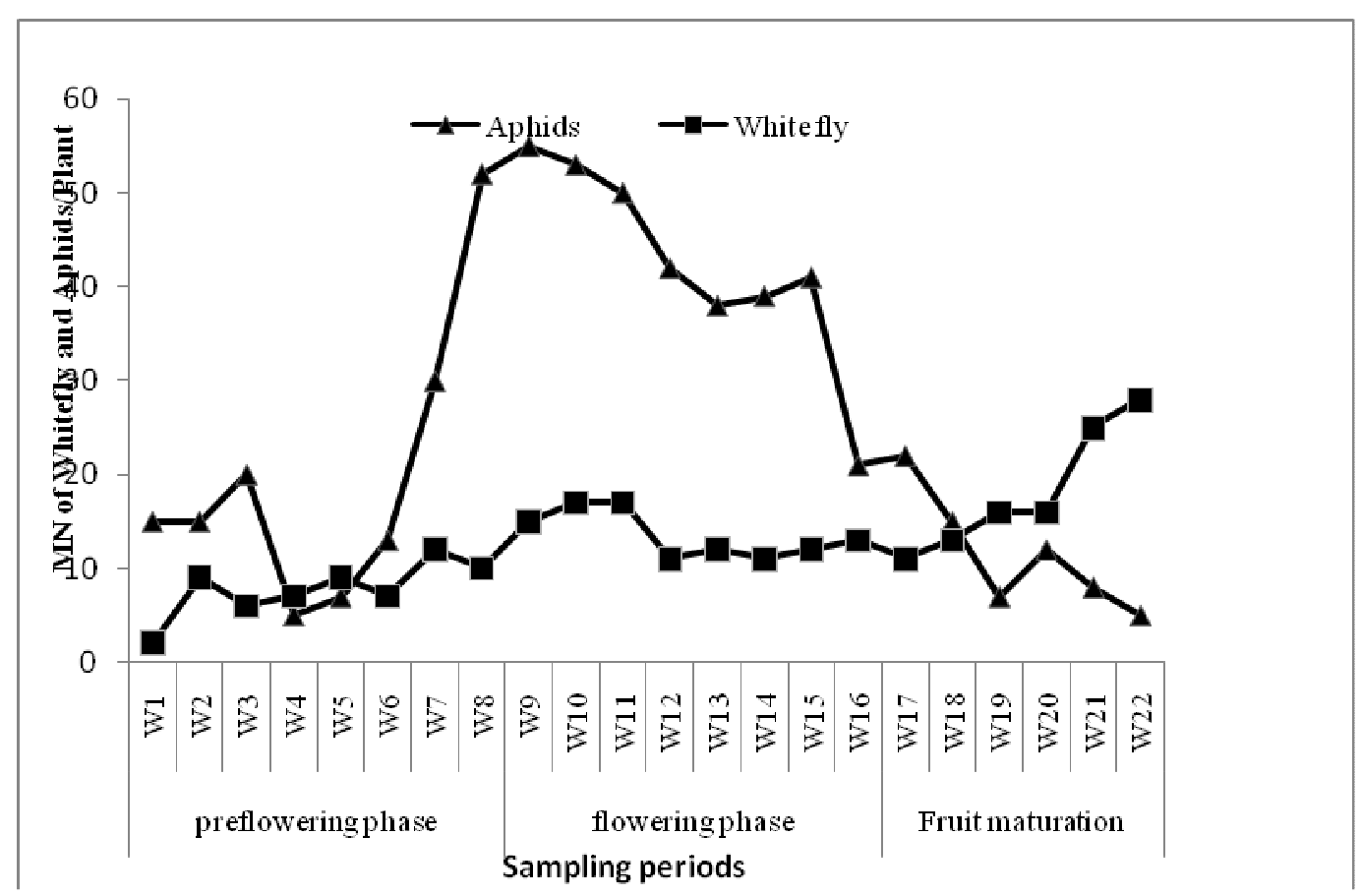

Figure 4: Temporal variation of plant louses and aleurod populations associated to yellow pepper in the experimental plot within the campus of the University of Yaoundé I between October 2007 and February 2008. MN = Mean Number. 


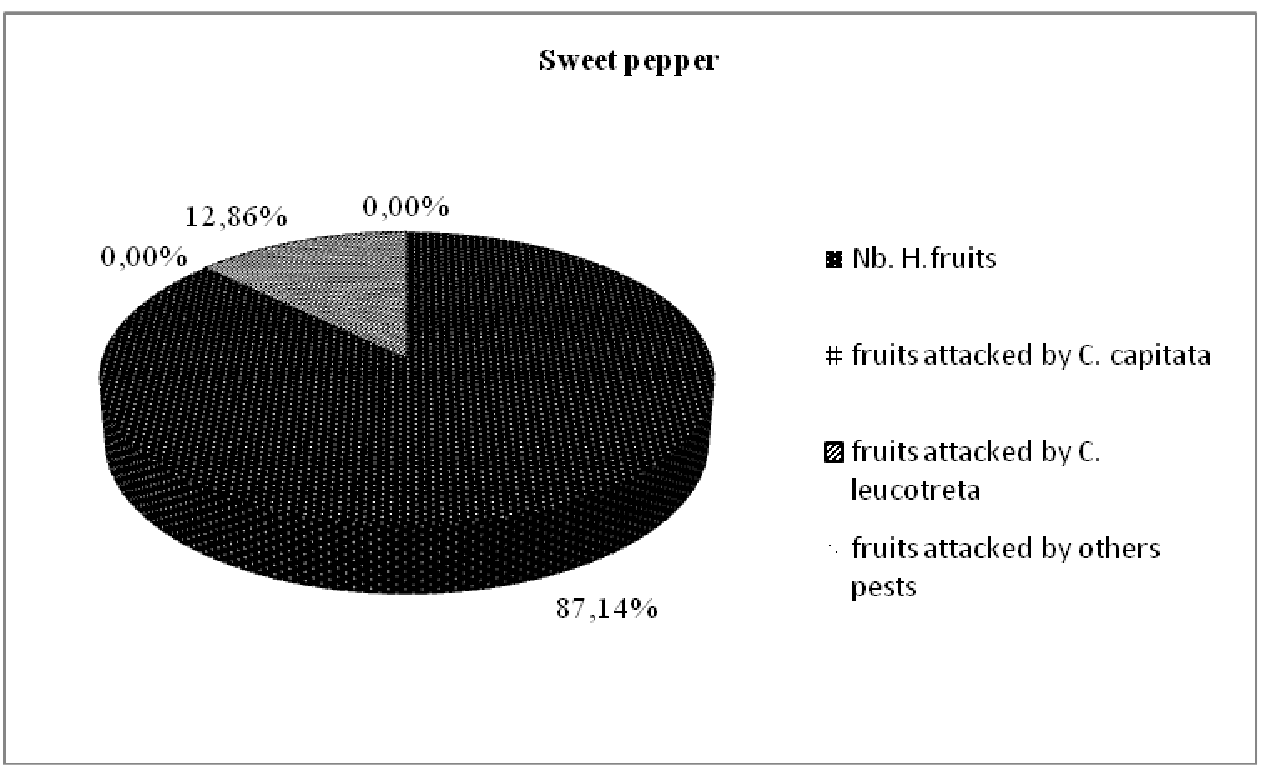

Figure 5: Rates of attack of specialists' fruit eating insects on the production of C. annuum (sweet pepper) in the experimental plot within the University of Yaoundé I campus, between December 2007 and January 2008. Nb. H. fruits = number of Healthy Fruits.

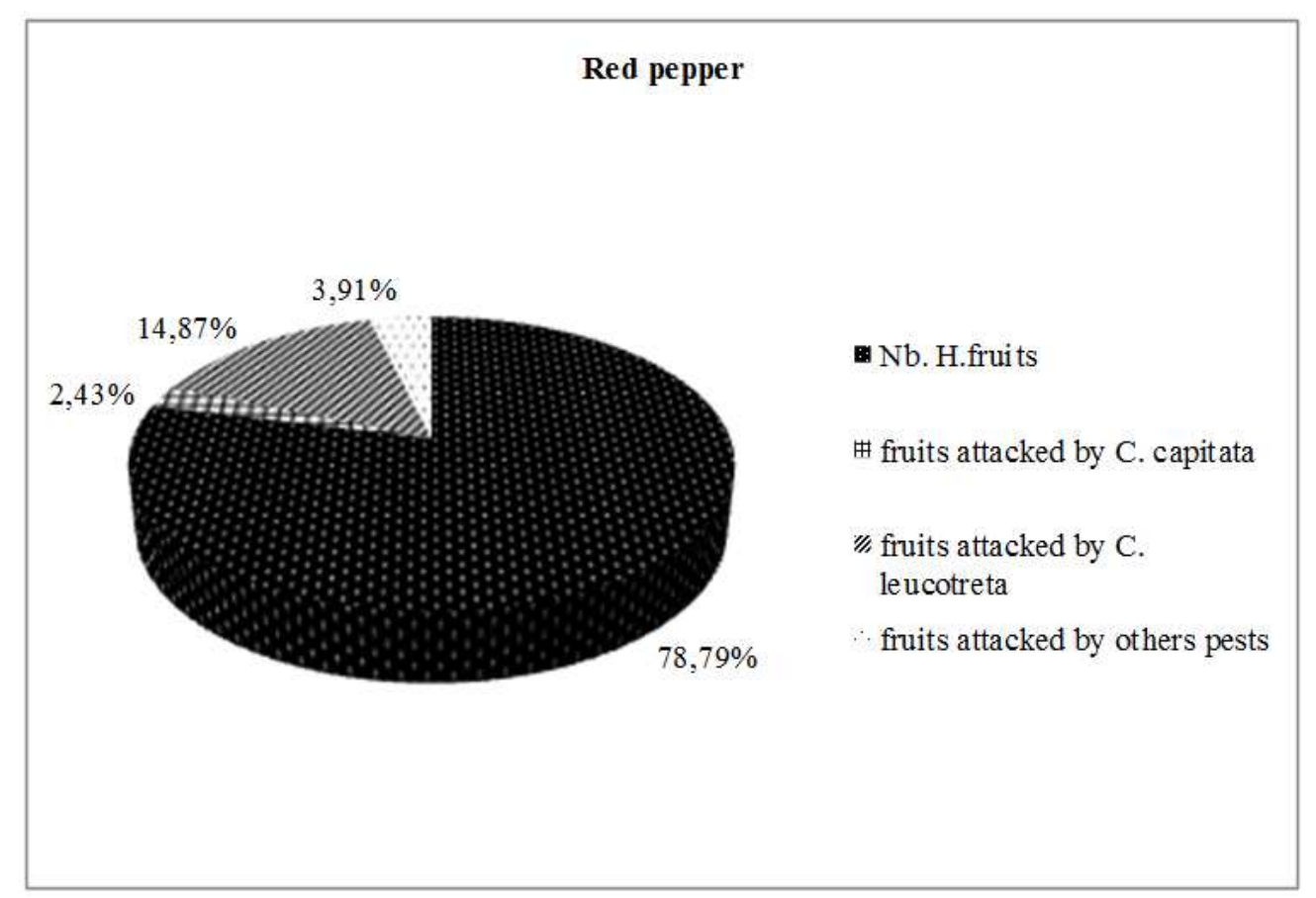

Figure 6: Attack rates of the specialists' fruit eating insects on the production of $C$. annuиm (Hot red pepper) in the experimental garden within the University of Yaoundé I campus, between December 2007 and February 2008. Nb. H. fruits = number of Healthy Fruits. 


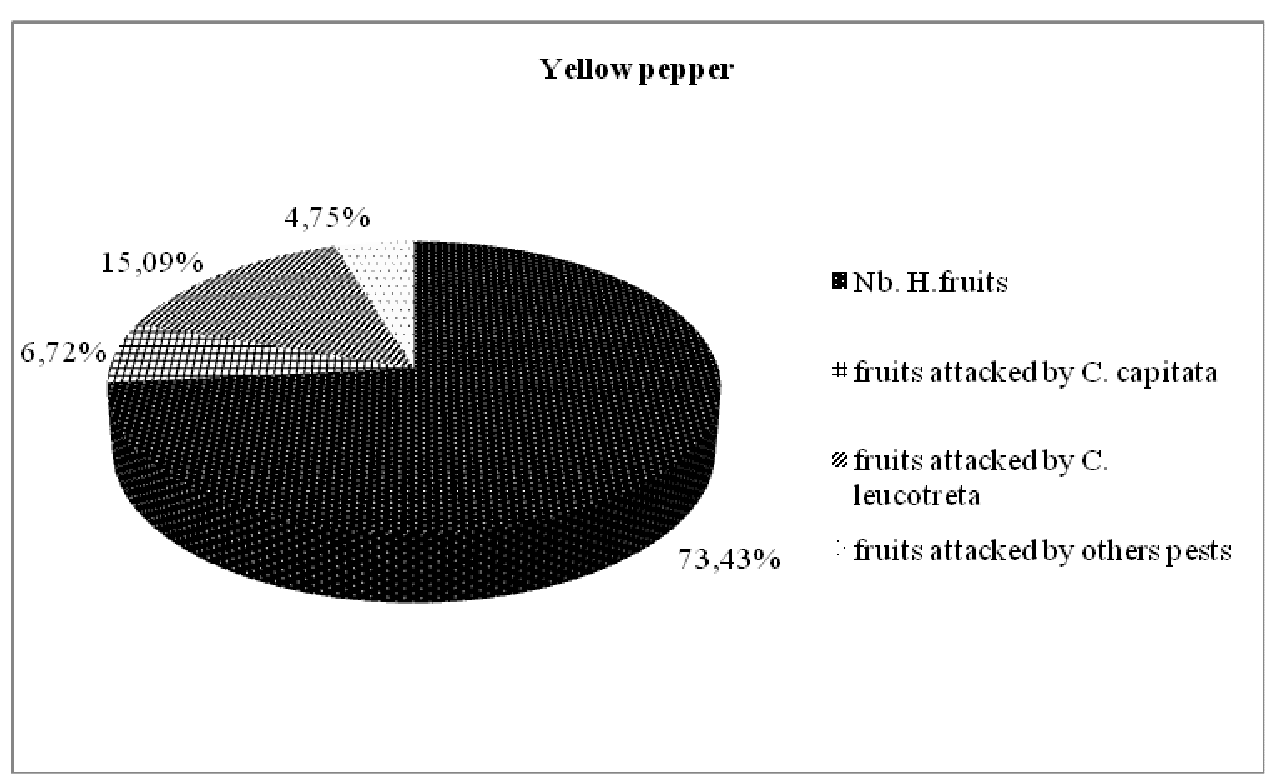

Figure 7: Attack rates of the specialists' fruit eating insects on the production of $C$. annuиm (yellow Pepper) in the experimental garden within the University in Yaoundé I campus, between December 2007 and February 2008. H. fruits = number of Healthy Fruits.

\section{DISCUSSION}

\section{Fauna associated with capsicum annuum}

The insectpests found on C. апnиит in our experimental garden was made up of seven orders: Hymenoptera, Hemiptera, Coleoptera, Diptera, Lepidoptera, Orthoptera, Thysanoptera. They destroyed plants by sucking their circulating juice, by eating directly the tissue of the plants or infesting them with viruses. Similar results were obtained by Bordat and Arvanitakis (2004) in West and Central Africa, Mayotte and $\mathrm{La}$ Réunion. These authors noticed that the most harmful pest of pepper belongs to the orders of Hemiptera, Diptera and Lepidoptera. On the contrary, Ted Turlings and Wackers (2004), as well as Van Mele et al. (2007) demonstrate the utility of some Hymenoptera predatorants like Oecophylla longinoda in controlling Mango fruit flies in Benin. The Hymenoptera Pheidole megacephala found in this work is considered as pest because of its significant role in transporting, protecting and dissimulating Hemiptera on pepper plants. This harmful activity of $P$. megacephala was also observed by Heumou (2008) on tomato
Lycopersicon esculentum in the area of Yaoundé. Djiéto-Lordon and Aléné (2006) noticed a similar harmful effect of Myrmicaria opaciventris, another ant in the market-gardening exploitations in sub-urban area of Yaoundé (Nkolondom).

\section{Population fluctuation of aphids and whiteflies associated to capsicum annuum}

During the life cycle of the plants, the aphid population varied significantly. Rainfall was not used to explain this variation because the plant was watered the same way throughout the sampling period. In all the three plant varieties, the population of aphids was lower than 10 individuals per plant during the $3^{\text {rd }}$ week after transplantation. This can be explained by the fact that, at this stage of the plant life cycle, the roots of the plants are not well developed and the plants have not yet accumulated enough sap. The plants at this stage will not have sufficient nutritional juice that insects can extract. During the second phase around the $4^{\text {th }}$ and $5^{\text {th }}$ weeks, the population grew up exponentially. This can be explained by the fact that at this stage of the 
life cycle, the plant's roots are well developed, the number of leaves is important for photosynthesis. As such, the youngest plants accumulate enough reserves for their flowering and fructification. Another explanation is that the ant Pheidole megacephala was abundant in the experimental plot, and it was very active in transporting and disseminating of aphids on plants. At the third phase of the life cycle, the population was maintained during the fructification period on red and yellow pepper except on green pepper where they started to decrease just after the flowering. The difference would be due to the fact that the yellow and the red pepper fructified for more than two months as opposed to green pepper on which the fructification period is less than two weeks. During the fourth phase of plant's life cycle, the aphids' population decreases substantially. This would be explained by the fact that at the end of the life cycle of the plants, the fruits that were produced by the plants consumed all the nutritional juice and the quantity of sap is no longer enough inside the plants to feed the aphids.Germano et al. (2006)'s work on Eggplant, Solanum melongena, clearly demonstrates the strong relationship with aphids. On the other hand, we noticed that during the third period of the plant's cycle, the presence of predators was abundant. Many Diptera Syrphidea larvae and Coleoptera Coccinelidea were observed feeding on the adult aphids. Ryckewaert and Fabre (2001) noticed that predators have a significant influence on the dynamics of the aphid population.

As opposed to aphids, the whitefly shows only two phases of variation during the life cycle of the plants. The first phases, between transplantation and the middle of flowering-maturation, the whitefly were low and increased gradually reaching a maximum of abundance at end of the fruit's maturation. These observations could be explained by the fact that on pepper, whiteflies (Bemisia tabaci) feed on the under surfaces of the youngest leaves. They lay their eggs on these leaves and at the end of plant's cycle, these eggs hatch and the youngest contribute to increase the whitefly population. Vayssière and Cauquil (2000) have made the same observations in Southern Africa where the whitefly population increases in old age leaves of cotton trees.

\section{Impact of fruit-eaten insects on the fruit loses of capsicum annuum}

In this study, the loss of harvest conferred to the fruit-eaten insects on yellow, red and sweet peppers is due to Tortricidae ( $C$. leucotreta) between 13 and $16 \%$ of total yield loss. The Dipterans $C$. capitata is only found on the hot pepper varieties of about $7 \%$ of total loss. These results are different from those of Mbanye (2000) which exclusively attributed $21 \%$ of yield loss on hot pepper to Dipterans. This difference could be due to the fact that infestation rate of the pest is significantly fluctuating during sampling season. Djiéto-Lordon and Aléné (2007) attributed them the status of major pests on pepper in the market-gardening exploitations in the area of Yaoundé. $C$. capitata is considered to be one of the most dangerous and invasive species of the Mediterranean countries threatening fruit trees such as apple and papaya (Kaspi et al., 2002; Rigamonti, 2004). This work shows that $C$. capitata is increasing its host plant species and its range of activities. It was recently adapted to $C$. annuum fruits in Cameroon.

\section{REFERENCES}

Betbeder-Matibet M. 1989. Catalogue des Insectes Nuisibles aux Cultures Vivrières d'Afrique, de Madagascar et des Mascareignes. IRAT / CIRAD : Montpellier.

Bordat D, Arvanitakis. 2004. Catalogue des Arthropodes des Cultures Légumières d'Afrique de l'Ouest, Centrale, Mayotte et Réunion. CIRAD : Montpellier.

Delvare G, Aberlenc HP. 1989. Les Insectes d'Afrique et d'Amérique Tropicale. Clés pour la Reconnaissance des Familles. Prifas : Montpellier. 
Djiéto-Lordon C, Aléné DC. 2002. Inventaire des insectes ravageurs et auxiliaires des cultures maraîchères dans la région de Yaoundé. Rapport - CIRAD Yaoundé, P. 35.

Djiéto-Lordon C, Aléné DC. 2006. Inventaire diagnostique des insectes de quelques cultures dans les exploitations maraîchères périurbaines dans la région de Yaoundé-Cameroun. PCP-Grand Sud Cameroun. Actes atelier de présentation des résultats de recherche participative. Yaoundé, février 21-23.

Djiéto-Lordon C, Aléné1 DC, Reboul JL. 2007. Contribution à la connaissance des insectes associés aux cultures maraîchères dans les environs de Yaoundé - Cameroun. Cam J. Biol. Biochem. Sc., 15: 1-13.

Etienne J, Delvare G, Aberlenc HP. 1992. Contribution à la connaissance de l'arthropofaune associée aux cultures de Casamance (Sénégal). Bolletino di Zoologia e di Bachicultura Ser. 24(2): 159-193.

ElonoAzang PS. 2007. Contribution à l'étude de l'Arthropofaune de Capsicum annuum Solanaceae LINNEE à Yaoundé Mémoire de DEA. Université de Yaoundé I., Cameroun, p.73.

GermanoL DL, Marcelo PJCZ, Carvalho C. 2006. Factors, affecting Herbivory of Thripspalmi (Thysanoptera: Thrypidae) and Aphis gossypii (Homoptera: Aphididae) on the Eggplant (Solanummelongena). An Inter. J. Biol. Tech, 49(3): 361-369.

Grubben GJH, Denton OA. 2004. Ressources Végétales de l'Afrique Tropicales 2. Légumes. Ed. Fondation PROTA/CTA : Pays-Bas.

Heumou CR. 2008. Contribution à la connaissance de la Bioécologie des carpophages associés à
Lycopersicon esculentum Miller (Solanacea) dans la zone urbaine de Yaoundé. Mémoire de DEA. Université de Yaoundé I, Cameroun, P. 64.

Kaspi R, Mossinsons, Drezner T, Kamensky B, Yuval B. 2002. Effects of larval diet on development rates and reproductive maturation of male and female Mediterranean fruit flies. Physiological Entomology, 27: 29-38.

Letouzey R. 1985. Notice de la Carte Phytogéographique du Cameroun au 1/500000. V. 4. Domaine de la Forêt Dense Humide Toujours Verte. ICIV : Toulouse ; 95-142.

Mbanye H. 2000. Contribution à l'étude des ravageurs et des insectes utiles de Lycopersicum esculentum Mill et Capsicum annum L Mémoire de maîtrise. Université de Yaoundé I, Cameroun p. 42.

Rigamonti IE. 2004. Contributions to the knowledge of Ceratitis capitata Wied. (Diptera, Tephritidae) in Northern ItalyI. Observation on the biology. Boll. Zool. Agr. Bachic Ser., 36(1) :89-100.

Ryckewaert P, Fabre F. 2001. Lutte Intégrée Contre les Ravageurs des Cultures Maraîchères à la Réunion, AMAS (ed). Foods and Agricultural Research Council, Réduit: Mauricius; 99-103.

Sunitha TR. 2007. Insect pests of Capsicum annuum var. frutescens (L.) and their management. Master thesis University of Agriculture Sciences Dharwad, Dharwad p. 67.

Ted Turlings CJ , Wackers F. 2004. Recruitment of Predators and Parasitoids by Herbivore-Injured Plants, Cardre RT, Millar JG (eds). Cambridge; 55.

Van Mele P, Vayssieres JF, VenTellingen E, Jan Vrolijks 2007. Effect of an African Weaner Ant, Oecophylla longinoda in controlling Mango fruit flies (DipteraTephritidea) in Benin. Economic Entomology, 100(3): 695-701. 